\title{
Entre Facas e Motosserras: problematizando práticas de pesquisa com História Oral
}

\author{
Caught between Knives and Chainsaws: \\ problematizing research practices with Oral History
}

Maria Ednéia Martins-Salandim

Karina Aparecida da Silva²

\begin{abstract}
'Universidade Estadual Paulista (UNESP), Faculdade de Ciências, Departamento de Matemática, Bauru, SP, Brasil. Autora correspondente: maria.edneia@unesp.br

${ }^{2}$ Universidade Estadual Paulista (UNESP), Faculdade de Ciências, Programa de Pós-Graduação em Educação para a Ciência, Bauru, SP, Brasil.
\end{abstract}

Resumo: O objetivo desse artigo é discutir práticas de pesquisa com a metodologia da História Oral no campo da Educação Matemática, a partir de problematizações decorrentes de uma pesquisa de mestrado. Essa metodologia, mobilizada mundialmente, foi difundida no Brasil por volta dos anos de 1970 e no campo da Educação Matemática no início dos anos 2000, com a criação do Grupo História Oral e Educação Matemática. Ainda que alguns procedimentos sejam comuns nas pesquisas que se valem da História Oral - gravação, textualização, cessão de direitos - o modo como ela é praticada articula-se com questões e necessidades de cada pesquisa. Na trajetória dessa pesquisa aqui em tela a metodologia não foi dada a priori, como mera técnica para produção de dados - nem faca, nem motosserra - como o professor Wagner Valente nos provocou, mas foi construção pautada em práticas de antecessores que exigiu estudo, atenção, respeito e sensibilidade.

Palavras-chave: História da educação matemática; Metodologia da pesquisa; Entrevista; Narrativa.

Abstract: This paper aims to discuss research practices with the aid of Oral History in the field of Mathematical Education, based on problematizations arising from a Master's thesis. This methodology, widely used worldwide, was disseminated in Brazil around the 1970s and, in the field of Mathematical Education, in the early 2000s, with the creation of the Oral History and Mathematical Education Group. Although some procedures are common in oral history research - recording, textualization, assignment of rights - it is implemented in particular manners to deal with the questions and needs in each study. In the development of this specific research, the methodology was not picked a priori, as a mere technique for data production - neither as a knife nor as a chainsaw - , as Professor Wagner Valente encouraged us to think. Instead, it was constructed according to the practice of predecessors and required study, attention, respect and sensitivity.

Keywords: History of mathematical education; Research methodology; Interview; Narrative.

Recebido em: 01/09/2019

Aprovado em: 01/04/2020 


\section{Introdução}

O objetivo desse artigo é problematizar práticas com a metodologia de pesquisa da História Oral que vem sendo praticada, em trajetória, no campo da Educação Matemática. Essa problematização é decorrente da dissertação de mestrado Primeiros cursos para formação de professores indígenas no estado de São Paulo: um estudo em história da educação matemática, de Silva (2019), cujo objetivo foi compreender e constituir uma versão histórica de como se deu o processo de criação desses cursos. Essas problematizações vão se constituindo no desenvolvimento da pesquisa de Silva (2019), mais particularmente após provocações feitas pelo professor Wagner Rodrigues Valente durante o XXI Encontro Brasileiro de Estudantes de Pós-Graduação em Educação Matemática (EBRAPEM), em 2017, sobre escolhas metodológicas de alguns grupos de pesquisa, orientadores e alunos, alertando, metaforicamente, sobre os casos em que uma motosserra é mobilizada só porque o orientador e/ou grupo de pesquisa utilizam-na, quando apenas uma faca poderia ser usada para realizar o mesmo trabalho. Essas discussões, fundamentais na formação de estudantes de pós-graduação e de novos pesquisadores, acompanharam-nos durante a realização da pesquisa aqui tematizada, ainda que o objetivo não fosse dar uma resposta à essa provocação, mas pensar e sistematizar sobre o modo como fomos construindo nosso percurso na pesquisa.

Na produção dos dados para essa pesquisa foram entrevistados, com base na História Oral, cinco participantes do processo de elaboração dos três primeiros cursos dessa natureza: o Magistério Indígena Novo Tempo (MagIND), desenvolvido entre 2002 e 2003, o curso de Formação Intercultural Superior do Professor Indígena (Fispi), desenvolvido entre 2005 e 2008 - ambos oferecidos pela Faculdade de Educação da USP em parceria com a Secretaria de Educação do Estado (SEE-SP) - e o Curso Intercultural Indígena, elaborado em 2014 pela Universidade Estadual Paulista (Unesp), o qual, embora tenha passado pelo processo de licitação da SEE-SP, não foi implementado.

$\mathrm{Na}$ construção metodológica do trabalho, muitas foram as inquietações sobre como enfrentar as questões da pesquisa, os encaminhamentos e escolhas metodológicas, a partir de estudos de práticas de História Oral de antecessores e às sensibilidades desenvolvidas ao longo da pesquisa em relação à temática e aos entrevistados envolvidos. Vianna (2014) problematiza essa temática ao dizer que para alguns autores a classificação da História Oral como metodologia de pesquisa qualitativa se faz necessária apenas para favorecer a definição em trabalhos acadêmicos e preservar estudantes de discussões que possam se tornar "acaloradas", ainda que isso nem sempre ocorra. Para o autor, é necessário que os pesquisadores situem a História Oral como uma prática, de modo que, a cada vez, o pesquisador não siga um determinado método, mas se paute pela prática de seus antecessores e descreva a prática que realizou. Nesse sentido, a ideia não é valermo-nos de facas ou motosserras disponíveis, mas, em um contínuo movimento entre práticas anteriores com a História Oral às quais temos acesso e contato, construirmos a metodologia da pesquisa. Como destaca Martins-Salandim (2018), as reflexões intencionais sobre metodologia de pesquisa nos auxiliam a pensar, articular e gerar novas temáticas de pesquisa, ao mesmo tempo em que novas temáticas requerem problematizações sobre práticas e metodologias anteriores. Assim, teceremos, a seguir, reflexões sobre a História Oral, para posteriormente, abordarmos particularidades da construção da metodologia de pesquisa de mestrado de Silva (2019), como um modo de pensar e praticar a História Oral em trajetória. 


\section{História Oral: sobre seu desenvolvimento e possibilidades}

As discussões mais sistemáticas sobre História Oral no campo da Educação Matemática brasileira não têm ainda duas décadas. Foi no começo dos anos 2000 que o Grupo História Oral e Educação Matemática (GHOEM) foi criado, passando a produzir pesquisas que mobilizam o referencial da História Oral. Ainda que a pesquisa de Silva (2019), a qual tomamos aqui como referência, seja de natureza historiográfica, destacamos que a História Oral tem sido mobilizada em pesquisas de diferentes naturezas. Isso ocorre tanto no âmbito do GHOEM - para produção de narrativas em situação de entrevistas -, quanto em diferentes áreas do conhecimento, tais como a Antropologia, a Sociologia, a História, tanto como metodologia de pesquisa, quanto como uma área independente dentre as disciplinas históricas ou como técnica de coleta de dados para constituição de acervos orais.

No Brasil, foi o campo das Ciências Sociais o pioneiro na mobilização da História Oral, ao buscar compreensões sobre os mecanismos sociais. Na década de 1970, com a criação da Associação Brasileira de História Oral (ABHO), foram ampliados os usos e as discussões sobre História Oral em universidades e em outras instituições do país. Por outro lado, a História Oral vem sendo pensada e aprofundada em âmbito mundial, como destacado por Thompson (2002), ao tematizar que em 1948 o historiador Allan Nevins, da Universidade de Colúmbia, em um projeto cujo objetivo era a gravação de memórias dos "grandes homens", iniciou a gravação de depoimentos de grandes personalidades da história norte-americana, papel que a História Oral desempenhou ao longo dos 20 anos seguintes. A partir da década de 1970, principalmente com a Antropologia, visando "[...] uma reconstrução mais realista e imparcial do passado, uma contestação ao relato tido como verdadeiro" (THOMPSON, 2002, p. 26), passou-se a gravar, por meio da História Oral, memórias de excluídos e marginalizados. Silva e Souza (2007) também destacam que, inicialmente, na História, a História Oral foi utilizada para delinear a história de sociedades sem registros escritos, uma vez que historiadores tradicionais censuravam qualquer outro tipo de possibilidade oriunda dos recursos orais. Vários autores apontam que a História Oral permite que as histórias de sujeitos - que não raras vezes se encontram às margens da história oficial, visto que não são reconhecidos como protagonistas de suas próprias histórias - sejam ouvidas. Llewellyn (2016) aponta que a História Oral ganhou força ao possibilitar que historiadores sociais "descobrissem as vozes" daqueles considerados invisíveis, cujas vidas foram ignoradas ou deliberadamente esquecidas. Para Thomson (2000), a História Oral promove um reconhecimento de grupos socialmente oprimidos de modo geral, pois incitam o reconhecimento público e possibilitam experiências que haviam sido anteriormente ignoradas ou silenciadas, e para Patai (2010), a História Oral permite ouvir histórias de indivíduos e grupos que de outra forma seriam ignoradas, além de convidar-nos a questionar nossos próprios pressupostos a respeito dos pontos de vista de outras pessoas e culturas. Segundo Mauad (2016), no Brasil, o contexto de redemocratização dos anos 1980 também foi fundamental para a organização da memória de diferentes movimentos sociais, partidos políticos, associações civis etc. Por outro lado, Baraldi (2003, p. 211) aponta que ao longo do desenvolvimento, a História Oral vem contribuindo com estudos que envolvem grupos e populações de segmentos médios, procurando "[...] evidenciar as tensões entre as histórias particulares e a cultura que as contextualizava". 
Assim, no campo da História, a História Oral transformou a forma de escrevê-la absorvendo o narrador para dentro da narrativa, tornando-o componente da história (PORTELLI, 1997). Como destacado por Neves (2001) os narradores são construtores da História - da poesia da História - aqueles, anônimos ou públicos, que deixaram sua marca em seu tempo:

[...] são líderes comunitários, empresários, militares, trabalhadores anônimos, jovens que cultivam utopias, mulheres que labutam no cotidiano da Maternidade e, simultaneamente, em profissões variadas, são líderes e militantes de movimentos étnicos, são educadores que participam da formação das novas gerações, são intelectuais que pensam e escrevem sobre os problemas da vida e do mundo, são artistas que através de seu ímpeto criativo representam realidades e sentimentos nas artes plásticas, nos projetos arquitetônicos, nos versos, nas composições musicais, são cientistas que plantam o progresso e a inovação tecnológica, são políticos que se integram à vida pública, adotando ou uma prática de estatura maior ou fazendo do espaço público local de práticas patrimonialistas (NEVES, 2001, p. 23).

O trabalho com a História Oral nos leva a defender o trabalho com as versões, a enfrentar os silenciamentos e a trilhar um processo de aprendizagem que estende o ouvido ao outro. Esse processo procura construir relações de escuta e cumplicidade entre quem narra uma história e quem a escuta. Segundo Garnica e Rolkouski (2014, p. 93), no momento da entrevista, ao solicitar ao nosso depoente que compartilhe suas histórias de vida conosco, estamos solicitando a ele que "[...] se constituía a nós naquele momento. Narrando-se o depoente constitui o seu 'si mesmo'". Esse momento não se trata de obter informações objetivas, mas de compartilhar as memórias de pessoas que nos confiam aquele momento de suas vidas, e isso exige conhecimento de quem se propõe a fazê-lo, escuta sensível e respeito à fala do outro. No mesmo sentido, Portelli (1997, p. 31) diz o que torna a História Oral diferente é que ela nos "[...] conta menos sobre eventos que sobre significados", não que ele não tenha validade factual, uma vez que estes sempre nos revelam facetas e elementos desconhecidos, mas que seus significados não são encontrados em outros tipos fontes. As fontes orais contam-nos não apenas o que o nosso colaborador fez, mas as suas intenções naquele momento, o que acreditava estar fazendo, assim como o que agora pensa que fez. O silêncio, o que as pessoas se lembram ou daquilo que se esquecem, são elementos que compõem a História por si só. Assim, as fontes orais e as narrativas, conforme MartinsSalandim (2012, p. 57):

Elas não são testemunhos no sentido daquilo que se viu ou presenciou (do fato 'tal como aconteceu'), mas um registro daquilo que se percebe, no presente, de algo que se vivenciou. Diante disso, é necessário aceitar teoricamente que um fato é aquilo que dele percebe-se.

Ao ser contada de uma multiplicidade de pontos de vista e ao problematizar as versões que aparecem como verdades científicas, a História Oral rompe com a ilusão de uma ciência neutra e de uma verdade única e absoluta. A História Oral contribui para que possamos compreender um cenário ou contexto espaço-temporal, sem defender uma perspectiva de verdade absoluta, uma vez que ela se inscreve não no domínio da veracidade, mas da plausibilidade (FERNANDES; GARNICA, 2014). Assim como na História - 
que se encontra desfavorável às certezas - ao mobilizarmos a História Oral não pensamos no indivíduo total ou unificado e a imparcialidade que outrora fora pleiteada pelos historiadores agora é substituída pela parcialidade do narrador. Como sugere Jenkins (2017), a obsessão pela verdade ou pelo fato é entendida como a busca pelo equilíbrio entre várias versões - um centro - que deve manter-se equilibrado mesmo com visões conflitantes. $O$ que muitos chamam de verdade nada mais é do que uma interpretação cristalizada, uma versão que se sobressaiu às demais - a versão dos dominantes. Sobre o "tomar partido" - a parcialidade do narrador - o próprio Portelli (1997, p. 33) afirma que o "[...] importante é não ser a memória apenas um depositário passivo de fatos, mas também um processo ativo de criação de significações", e essas significações podem ocorrer a partir de mudanças forjadas pelas questões de cada época, assim como, pela memória do depoente. Essas significações, elaboradas a partir das intenções e possibilidades singulares de cada pessoa, e do modo como cada uma percebe o mundo, faz com o mundo seja lido de diferentes maneiras. Dessa forma, quando narramos, atravessados por nossas possibilidades singulares e significações, "[...] explicamos nossas próprias ações e os eventos humanos que aconteceram à nossa volta, criamos mundos. Esses mundos estão aprisionados nas formas de narrativa que a cultura em particular nos oferece" (GARNICA; ROLKOUSKI, 2014, p. 94).

A História Oral como metodologia, ao possibilitar a constituição de fontes a partir dos registros de memória - como a (re)construção que evoca um passado pelas lentes do presente enfrenta as ambiguidades percebidas - as significações - nesse processo de organização das experiências passadas. Para Hartmann (2016), essas ambiguidades constituem o próprio campo da História. Vários autores se dispuseram, e ainda se dispõem, a discutir o papel da memória em relação à História. Para Nora (1993, p. 14) "[...] tudo o que é chamado hoje de memória não é, portanto, memória, mas já história [...]. A necessidade de memória é uma "necessidade de história". O autor, no entanto, afirma que se deve levar em consideração a diferença entre memória verdadeira e a memória transformada por sua passagem em História. Segundo o autor, a memória verdadeira, "[...] abrigada nos gestos e nos hábitos, nos ofícios onde se transmitem os saberes do silêncio" (NORA, 1993, p. 14), é espontânea e imediata, enquanto a memória transformada por sua passagem em História é quase o contrário: "voluntária e deliberada, vivida como um dever". Já Ricoeur (2007) propõe que seja atribuída à memória uma função mais positiva em relação à História, uma vez que há nesse processo uma relação mútua. Para o autor, a História efetua um trabalho crítico em relação ao registro provindos da memória, enquanto essa permite ao historiador uma visão retrospectiva do passado. Para Le Goff (2001), do mesmo modo que o passado não é História, a memória também não é História, mas é seu objeto, e mesmo sendo seu objeto, é através da memória que a História é construída. Entretanto, há autores, como Vianna (2014, p. 80), que entendem que essa "[...] preocupação exagerada com o par memória-história", nada mais é do que isso: uma preocupação exagerada:

Devemos aprofundar nossos estudos em relação às diferenciações possíveis entre história e memória. Isso parece interessar de modo particular alguns historiadores, principalmente a aqueles que parecem não gostar muito da memória e que, embora não tenham como meta transformar a História em uma Ciência com' $C$ ', tendem a ver 'pouca ciência' nas práticas com a memória ou, quando cientes do paradoxo evitam usar, nas suas críticas, a palavra 'ciência', ou a expressão 'pouco rigor' no tratamento dos fatos. Mas, francamente, eu não me incomodo nada que se faça confusão entre 
memória e história [...]. Não consigo perceber o que é que se ganha, em termos científicos, quando a gente tem que eliminar qualquer confusão 'a priori' (VIANNA, 2014, p. 80).

De um modo geral, os autores que se valem da História Oral, acreditam na legitimação e no cotejamento entre as diversas fontes, isso sem haver a necessidade de uma hierarquização entre elas. Nesse sentido, Garnica (2004, p. 78, grifo nosso) afirma que:

Historiadores conceituados - tanto antigos como contemporâneos - afirmam sobre as vantagens da utilização de várias fontes para a compreensão do mundo, pelo viés da História: o estudo dos homens no tempo. Negar os arquivos escritos como recurso de pesquisa seria um equívoco tão alarmante quanto negar a importância da oralidade para entender a temporalidade e, nessa temporalidade, as circunstâncias humanas.

A realização de entrevistas, por si só, não compõe uma operação historiográfica, mas o registro das memórias dos colaboradores das pesquisas, juntamente com o cotejamento entre várias fontes, apoiados em uma determinada metodologia, forma um conjunto de ações que se constituem como uma operação historiográfica.

Assim como Garnica (2005), entendemos que há a necessidade de uma distinção entre História Oral como recurso metodológico para trabalhos de caráter geral e História Oral como recurso para trabalhos de natureza historiográfica, isto é, aqueles que visam a elaboração etnográfica. Segundo o autor, ao utilizarmos a História Oral como fundante teórico-metodológico para pesquisas de teor historiográfico: "[...] os estudos têm em comum a tendência a não 'coisificar', 'factualizar' - e, decididamente, a não heroificar - os indivíduos-depoentes, mas preservá-los em sua integridade de sujeitos, registrando uma rica pluralidade de pontos de vista: distintas versões da História." (GARNICA, 2005, p. 5).

Essa pluralidade de pontos de vista que a História Oral, em estudos de natureza historiográfica, se propõe a registrar - "[...] tratando de procurar pela verdade das histórias, (re)constituindo-as como versões, analisando como se impõem os regimes de verdade que cada uma dessas versões cria e faz valer" (GARNICA, 2005, p. 6) - é um dos principais pontos para que possamos explicitar com mais clareza o que entendemos por História Oral e como podemos utilizá-la como recurso para nossas pesquisas historiográficas. Vários autores, assim como Albuquerque Júnior (2007, p. 233), entendem que no final do processo de pesquisa historiográfica sempre é reafirmado o "[...] poder dos que escrevem, dos que dominam a escrita sobre os que apenas falam, os que apenas verbalizam seus conhecimentos e experiências". Ainda segundo o autor:

A História, que também não consegue se dissociar da escritura, também já redescobriu, nesse momento, a voz do passado, a história oral. O mito da voz do povo, dos dominados, dos marginalizados, os despossuídos, volta a servir de tropo narrativo que dá legitimidade e unicidade ao discurso da História. [...]. Contribuindo de forma inequívoca para que novas falas fossem encenadas pelos historiadores e seus personagens, para que novos olhares sobre o passado fossem possíveis, dentro da Universidade e das instituições que agrupam os historiadores, a história oral é, sem dúvida, vitoriosa. Mas terá ela conseguido converter a derrota histórica das oralidades para a escritura? Não me parece, até porque ela seria um agente infiltrado, que continua em busca dos segredos dos que falam para escrevê-los, tornando-os documentos, inscrevendo-se como monumentos (ALBUQUERQUE JÚNIOR, 2007, p. 234). 
Entendemos que o fato de vivermos numa sociedade de escrita não deve impedir historiadores/pesquisadores de ampliar e diversificar fontes para que se possa compreender certos contextos e situações. O objetivo da História Oral é constituir - quando mobilizada com finalidades historiográficas - através das memórias de depoentes, várias versões, que juntas com as demais fontes alimentam a atribuição de significados de um certo contexto espaço temporal que buscamos compreender. A prática da História Oral tem tratado de alguns procedimentos e negociações para a gravação da entrevista, transcrição, textualização e carta de cessão de direitos.

\section{A História Oral como Metodologia de Pesquisa em Trajetória no GHOEM: algumas apropriações}

O Grupo de Pesquisa História Oral e Educação Matemática (GHOEM) tem como uma de suas intenções estudar as possibilidades de utilização da História Oral como um recurso teórico-metodológico para as pesquisas em Educação Matemática. Vale ressaltar que mesmo mantendo características similares à História Oral praticada em outras áreas do conhecimento, a História Oral que praticamos no GHOEM - ao apoiarmo-nos nas novas abordagens e questões que surgem na trajetória das investigações - vai metamorfoseandose, ressignificando-se frente aos nossos objetos e objetivos de estudo, configurando-se como uma maneira particular de pensar e conduzir pesquisas.

Assim, assumimos que a História Oral é uma metodologia de pesquisa qualitativa, concebendo o adjetivo qualitativa como se referindo a pesquisas que reconhecem:

(a) a transitoriedade de seus resultados; (b) a impossibilidade de uma hipótese $a$ priori, cujo objetivo da pesquisa será comprovar ou refutar; (c) a não neutralidade do pesquisador que, no processo interpretativo, vale-se de suas perspectivas e filtros vivenciais prévios dos quais não consegue se desvencilhar; (d) que a constituição de suas compreensões dá-se não como resultado, mas numa trajetória em que essas mesmas compreensões e também os meios de obtê-la podem ser (re)configuradas; e (e) a impossibilidade de estabelecer regulamentações, em procedimentos sistemáticos, prévios, estáticos e generalistas (GARNICA, 2005, p. 7).

Nosso entendimento é que metodologia de pesquisa não é uma mera elaboração de algoritmos ou procedimentos e sim, um recurso efetivado ao mesmo tempo em que pesquisas específicas são desenvolvidas com esse recurso. Para nós, metodologia é ação, caminho, fluxo, construção. Assim, o tema e as fontes vão exigindo um ou outro tratamento específico, e no decorrer de cada pesquisa estudamos a validade e viabilidade da mobilização da História Oral, assim como suas vantagens e desvantagens. Ao problematizarmos nossos procedimentos durante o trabalho, somos livres para complementar, alterar ou excluir elementos que para outros membros são tidos como suficientes e adequados. Essas escolhas, e a problematização desse processo, é que dá flexibilidade e dinamismo para nossas pesquisas. Não há 'regulamentos' ou receitas de como constituir e tratar as entrevistas como fontes para pesquisas, porém, as discussões no GHOEM sobre as potencialidades da História Oral, assim como seus impasses, constituíram algumas "regulações", as quais nos orientam quanto aos nossos objetivos e ações no decorrer da pesquisa. 
Assim, os integrantes do GHOEM, como nós, têm compartilhado algumas regulações e procedimentos orientadores que envolvem esclarecer aos entrevistados as intenções de nossa pesquisa e todos os trâmites durante e após as entrevistas, como a conferência das textualizações pelo entrevistado e a assinatura de carta de cessão de direitos sobre a gravação da entrevista e sobre o texto dela resultante, com ou sem restrições de uso. Vale ressaltar que as interpretações que fazemos a partir das narrativas são de inteira responsabilidade do pesquisador, e que ao explicitarmos nossos procedimentos e princípios éticos não estamos tentando nos isentar de tal responsabilidade. Esses pressupostos relacionam-se não apenas com questões acerca de procedimentos metodológicos para a criação e tratamento das fontes orais - da escolha de depoentes, de como conduzir a entrevista, realizar a transcrição e textualização (edição da entrevista transcrita) - mas também, relacionadas à sua divulgação em nossas pesquisas - via-de-regra apresentadas na íntegra - e à sua disponibilização.

O processo de negociação ocorre desde o primeiro contato com o depoente. Caso aceitem colaborar com a nossa pesquisa, a data e o local devem ser negociados. Durante a entrevista, esse processo de adaptação também se faz necessário, seja em relação às perguntas do roteiro ou ao próprio modo de conduzir a entrevista. Porém, a principal negociação acontece frente à validação do texto feita pela pessoa que concedeu a entrevista, o que pode afetar de modo decisivo a textualização. Sobre esse processo de negociação, Garnica e Martins-Salandim (2016, p. 190) afirmam: "[...] muitas vezes, os entrevistados usam seus espaços de poder, o que ocorre visivelmente no momento em que narram - e, portanto, decidem o que querem narrar - e no momento em que conferem a textualização exercitando seu poder de veto."

O trabalho com a memória de nossos depoentes faz com que operemos ao mesmo tempo com uma fonte que é também objeto de análise. Além disso, nossos trabalhos, compostos por narrativas, são também narrativas que, pautados pelo esforço para constituir documentos históricos, servirão como fontes a outras compreensões. As textualizações são textos constituídos a partir da leitura que cada pesquisador faz das entrevistas transcritas. Elas carregam uma série de possibilidade de análise e as significações dependem daquele que está interessado em entender (GONZALES, 2017). A textualização pode, portanto, constituir a parte mais significativa da análise do trabalho de pesquisa.

No entanto, vários autores nos alertam quanto às possíveis armadilhas encontradas no processo de análise. Garnica e Martins-Salandim (2016) apontam ser um equívoco exigir que o depoente conduza uma análise, uma vez que essa função é somente do pesquisador. Delgado (2006, p. 30) também nos alerta quanto ao fascínio pela memória relatada:

Também o fascínio que a memória traduzida em História provoca nos entrevistadores e nos pesquisadores deve ser considerado. Cuidados especiais precisam ser adotados para que o pesquisador não se torne refém do depoimento recolhido, em prejuízo de sua capacidade analítica.

Desde a sua constituição, em 2002, integrantes do GHOEM têm mobilizado a oralidade como recurso para a constituição de fontes, dentre elas fontes historiográficas. Do diálogo e interlocuções com diversas áreas do conhecimento, além de novas configurações a partir de cada abordagem e das questões que surgem na trajetória das investigações, surgiu o que temos chamado de História Oral em Educação Matemática. Nossas análises, como destacam Garnica e Martins-Salandim (2016), são disparadas a partir das textualizações das entrevistas, 
sendo suscitada num processo interpretativo que envolve as intenções da pesquisa e as possibilidades e o modo como o pesquisador concebe e percebe o mundo. As narrativas produzidas no GHOEM, através da História Oral, têm nos auxiliado na compreensão, de modo geral, do campo no qual se negociam os significados entre Matemática, ensino e aprendizagem.

\section{A História Oral na Trajetória de uma Pesquisa Específica}

Todo o processo de elaboração do projeto e desenvolvimento da pesquisa de mestrado Primeiros cursos para formação de professores indígenas no Estado de São Paulo: um estudo em história da educação matemática, da autoria de Silva (2019), foi perpassado por problematizações tanto temática quanto metodológicas. Tendo como uma inquietação inicial o modo como questões sobre educação indígena apareciam nos cursos de formação de professores, iniciamos aproximações com uma das linhas de pesquisa do GHOEM Projeto: mapeamento da formação e atuação de professores que ensinam/ensinaram matemática no Brasil - linha à qual se vinculam estudos de como são/eram formados e como atuam/ atuaram professores de Matemática no Brasil em diferentes instituições e níveis escolares, em distintos tempos e espaços. Após essa aproximação e uma imersão em leituras sobre a História Oral e historiografia, nosso objetivo se tornou compreender e constituir uma versão histórica de como se deu o processo de criação dos primeiros cursos que formaram professores indígenas no estado de São Paulo.

Visando produzir dados para essa pesquisa entrevistamos pessoas que participaram do processo de criação desses cursos. Nosso acesso aos possíveis nomes de entrevistados deu-se tanto a partir de documentos disponibilizados no site ${ }^{1}$ da Secretaria da Educação do Estado de São Paulo (SEE-SP), na bibliografia consultada, quanto pelo critério de rede. Esse critério, também chamado bola de neve, se dá quando uma pessoa indica ao pesquisador o nome de possíveis depoentes ou os entrevistados vão indicando outros. Nossos contatos iniciais foram via e-mail, telefone ou redes sociais, momentos nos quais explicitamos nossos objetivos e procedimentos de pesquisa, esclarecimentos que foram nos sensibilizando ainda mais tanto em relação à temática da pesquisa quanto à História Oral.

Essas sensibilizações seguiram a partir de um exercício específico quando da preparação para as entrevistas que visava não apenas elaborar um roteiro adequado para às questões da pesquisa, mas também possibilitar uma apropriação desse roteiro - já que esse era um momento bastante angustiante para quem entrevistaria alguém pela primeira vez. A partir de um rol de temas e questões, fomos nos perguntando e justificando sua adequação ou não para o que nossa pergunta de pesquisa perguntava e em relação ao perfil dos possíveis entrevistados e refletíamos sobre o modo de fazer a pergunta. Assim, fomos pensando em roteiros com questões mais gerais e que seriam lapidados antes e entre cada entrevista. Nosso roteiro para as entrevistas tematizava, além da formação dos entrevistados, algumas questões específicas, devido ao papel desempenhado na proposição dos cursos que tematizamos, outras, eram comuns, mas, com sentidos diferentes. Ainda que pela imersão nas leituras já soubéssemos sobre a importância do roteiro, sua complexidade só foi melhor percebida quando realizamos esse exercício de debruçarmo-nos sobre ele, de problematizarmos cada questão relativa a cada entrevistado e pensar em roteiros diferentes, 
de acordo com o que se buscava compreender junto com cada um dos entrevistados, incluindo, inclusive, novas questões a partir das entrevistas já realizadas. Pudemos perceber que essa problematização dos roteiros, tanto tornava-os mais adequados a cada entrevista e à questão de pesquisa, quanto nos ajudava na organização para o momento da gravação. Além disso, fomos compreendendo a importância dos nossos ouvidos, a nos guiarem durante todo o processo de pesquisa. Saber fazer a pergunta também implicava saber ouvir.

Duas falas de Marco Polo, personagem de As cidades invisíveis, de Ítalo Calvino, nos afetaram durante essas reflexões sobre a preparação e a realização das entrevistas. "Quem comanda a narração não é a voz: é o ouvido" e "Eu falo, eu falo, mas quem me ouve retém somente as palavras que deseja" (CALVINO, 1990, p. 123), diz Marco Polo, ao tentar descrever ao imperador Kublai Khan as muitas cidades do seu império, que o mesmo, de tão ocupado, não pode visitar por si próprio. Da mesma maneira, um apontamento de Marc Bloch (BLOCH, 2001, p. 104) acerca da condição momentânea do observador: "[...] com poucas exceções, não se vê, não se ouve bem a não ser o que se esperava de fato perceber", nos disparam reflexões sobre a problematização das questões de um roteiro e os caminhos que ela nos possibilita. Essas leituras nos auxiliaram a problematizar, em nossa pesquisa, não só como preparar as entrevistas e fazer as perguntas, mas também em como temos ouvido o outro, não só no momento da gravação, como também nos processos de transcrição, textualização e nas análises. Não damos voz a nossos colaboradores, damos ouvidos às suas histórias, em uma construção conjunta no momento da entrevista, em um diálogo.

Como aponta Thompson (2002), realizar um registro subjetivo de como o colaborador olha e narra suas experiências, é um forte argumento para que optemos por menos direcionamentos e intervenções durante o momento dessa partilha. No entanto, o autor adverte: uma entrevista completamente livre não pode existir. "Apenas para começar, já é preciso um contexto social, o objetivo deve ser explicado, e pelo menos uma pergunta inicial deve ser feita" (THOMPSON, 2002, p. 258). Nesse mesmo sentido, Gonzales (2017) afirma que a própria elaboração do roteiro está repleta de intencionalidades do pesquisador, em falar de coisas que são de seu interesse, do interesse da sua pesquisa. Assim, entendemos que é necessário que o entrevistador saiba ponderar entre a busca de uma evidência objetiva, em um questionário inflexível, e o não direcionamento total, deixando o colaborador às cegas acerca de seus interesses enquanto pesquisador.

Mas, tão importante quanto tudo isso é a percepção de que há uma relação entre o que se sabe antes da entrevista e a possibilidade de obter conhecimentos novos durante esse momento. É por isso que o pesquisador deve estar preparado e demonstrar conhecimento suficiente do tema, mas, criar uma imagem romantizada do momento da entrevista é um equívoco; esse momento é único e, às vezes, pouco se assemelha às dicas que encontramos em manuais sobre condução de uma entrevista ou de orientadores e colegas experientes. Mesmo cientes de que uma previsão desses momentos seja impossível, e esclarecendo que essa nunca foi nossa intenção, buscamos problematizar as questões presentes nos roteiros de cada entrevista, e pensar quais respostas nossas questões possibilitavam, e se possibilitavam a constituição de dados para a nossa pesquisa. A intenção desse exercícioera fazer do momento que antecede as entrevistas um momento de reflexão, pautado nas expectativas e desafios encontrados nas entrevistas anteriores, sobre o que esperávamos com cada uma dessas questões, uma vez que era nossa intenção produzir fontes para uma pesquisa específica, com seus objetivos e inquietações específicas, mas também, constituir 
dados que poderão ser utilizados em outras pesquisas. Fomos percebendo que uma postura mais aberta, mais dialogada na entrevista, vai se estabelecendo conforme vamos tendo mais experiências em realizar entrevistas. Fomos percebendo que o momento da entrevista é único, e que nossas preocupações iniciais, sobre se lembraríamos das nossas questões no momento da gravação, vão se amenizando quando tencionamos mais o roteiro. Por outro lado, a realização das entrevistas, e as experiências com elas, vão nos levando a perceber esse momento como um momento de muita sensibilidade, de cumplicidade, de escuta, muito mais de que o momento da pergunta certa. O modo de perguntar vai surgindo conforme o ouvido se coloca em escuta em cada uma das entrevistas, em suas singularidades. Assim, o debruçar-se sobre o que o roteiro pergunta, e perguntar-se sobre ele, foi essencial, não só para fazer as perguntas na entrevista, mas para preparar, sensibilizar a escuta, durante todo o processo da pesquisa.

Nossa primeira entrevistada foi a professora Claudia Georgia Sabba, na época doutoranda da Universidade de São Paulo (USP), que pensou e conduziu, junto ao seu grupo de pesquisa, Grupo de Estudo e Pesquisa em Etnomatemática (GEPEm), os dois cursos de formação - Magistério Indígena Novo Tempo (MagIND) e Formação Intercultural Superior do Professor Indígena (Fispi). Depois entrevistamos o professor Adriano César Rodrigues Campos, representante indígena no Núcleo Educacional Indígena (NEI) da SEE-SP, que participou de ambos os cursos. A terceira entrevista foi com o professor Mauro Cherobim, antropólogo do NEI no período de criação dos cursos, e que foi convidado pela SEE-SP para redigir uma proposta do ementário e dos componentes curriculares do projeto que viria a se tornar o MagIND. A quarta entrevistada foi a professora Deusdith Bueno Veloso, ex-assessora da SEE-SP, apontada por todos os entrevistados como muito atuante na proposição dos cursos de formação. E a última entrevista, realizada bem posteriormente, foi com o professor Vitor Machado, do câmpus de Bauru da Unesp, que participou da elaboração de uma proposta para o oferecimento de um terceiro curso, em 2014, em continuidade no processo de formação de professores indígenas. Diferentes foram os desafios na condução de entrevista, uma vez que cada entrevista era única, num encontro entre modos de narrar e ouvir do entrevistador e entrevistado.

Após a transcrição das entrevistas gravadas, passamos a pensar e a realizar as textualizações - as quais, aprovadas pelos entrevistados, foram publicadas como parte da dissertação. Carmen Aranha (ARANHA, 2006, p. 49) faz uma analogia entre a História Oral, principalmente sobre a tarefa de transcrever, textualizar e apresentar obras de arte durante a visitação do público em um museu: as obras não são autoexplicativas, sendo assim, é necessária uma apresentação da obra, como um tecido mediador que busca "[...] compor possíveis interações culturais entre o visitante e a obra de arte, um dia materializada pelo artista". Da mesma forma, as textualizações - elaboradas a partir das entrevistas transcritas são mediadas entre o leitor do trabalho e a entrevista gravada, concedida pelo entrevistado em determinadas circunstâncias. Uma analogia quanto à restauração das obras de arte também é feita pela autora: o mais singelo retoque pode comprometer a obra, da mesma forma que a mais simples mudança no texto pode alterar o discurso do depoente. Ainda que cientes dessa afirmação, nossa prática em relação aos depoimentos, principalmente em relação à entrevista do professor Mauro, não pôde seguir esse cuidado que Aranha (2006) propõe. O registro de suas memórias foi reorganizado e agrupado em dois momentos da sua vida na textualização, uma vez que suas lembranças se entrelaçam a todo o momento. Essa 
nossa opção se justifica pela necessidade e liberdade da pesquisadora quanto à reestruturação da narrativa por passagens temporais e por temas, a qual foi reconhecida como possível pelo entrevistado.

Ademais, optamos também por incorporar várias notas de rodapé nas narrativas produzidas, com a finalidade de complementar as informações fornecidas por nossos depoentes. Muitas dessas notas não seriam necessárias para o entendimento do nosso tema de pesquisa, mas como entendemos que essas textualizações são fontes historiográficas e que, mesmo produzidas para uma pesquisa específica poderão ser utilizados em outras pesquisas, optamos por incorporá-las. Essas notas de rodapé se tornaram o nosso principal trabalho na textualização das entrevistas, uma vez que nos propusemos a relacionar várias informações entre as próprias narrativas, assim como entre a legislação vigente à época dos cursos, com o contexto histórico e todas as outras relações que percebemos necessárias. Mesmo não sendo nossa intenção inicial, essas notas disparam inúmeras reflexões e nos direcionaram para novas possibilidades analíticas. Bloch (2001, p. 95) tematiza as potencialidades do conhecimento produzido em suas "[...] humildes notas, pequenas e minuciosas referências, de que tantos espíritos ilustrados zombam atualmente".

Ainda segundo Bloch (2001), a ciência histórica - diferentemente da história, coextensiva à vida humana - é um fenômeno histórico, submetido às condições históricas. Essas condições são legítimas, mas também são frágeis. O autor afirma que as sociedades só conseguirão se organizar racionalmente "[...] lutando corpo a corpo com os dois principais responsáveis pelo esquecimento e pela ignorância: a negligência, que extravia os documentos; e a paixão pelo sigilo" (BLOCH, 2001, p. 85).

Comecemos então pela não localização de documentos. Mesmo não sendo um dos nossos objetos de análise, inicialmente esperávamos ter acesso aos projetos dos cursos MagIND e Fispi, assim como os demais projetos enviados para a Secretaria da Educação durante o período de licitação para o oferecimento dos cursos. Menos provável ainda, esperávamos ter acesso às pautas e registros das reuniões que aconteceram durante as negociações para a criação desses cursos. Foram várias nossas tentativas de encontrar alguns desses documentos, para isso enviamos e-mails ou ligamos para funcionários da Biblioteca da Faculdade de Educação da Universidade de São Paulo (FE-USP), do Departamento de Educação Matemática da USP, do Laboratório da Faculdade de Educação, da Secretaria da Educação do estado de São Paulo (SEE-SP) e do Centro de Referência em Educação Mario Covas (CRE), além de contatos com membros do Grupo de Estudo e Pesquisa em Etnomatemática (GEPEm), do Grupo de Pesquisa de História da Educação Matemática (Ghemat), e também com os próprios depoentes. Os documentos, assim como todos os outros materiais acerca da Educação Indígena do estado de São Paulo que se encontravam na biblioteca da USP, não se localizam mais. Os funcionários, assim como membros do GEPEm, não souberam nos informar quanto a sua localização. Por fim, uma funcionária do Centro de Referência em Educação Mario Covas, informou-nos que se os documentos estivessem lá, o que ela não poderia confirmar, estariam todos encaixotados devido a uma mudança repentina para outro prédio e estava prevista uma organização desses materiais apenas para o final do ano de 2018.

O segundo tema que Bloch (2001) aponta como responsável pelo sigilo e ignorância da História é o sigilo. Dentre várias outras formas, tomaremos aqui, como o silêncio frente às possibilidades de colaborar com pesquisas que buscam constituir fontes históricas. Assim 
como no momento da entrevista e ao ceder ou não os direitos sobre a entrevista, o possível depoente usa seu espaço de poder, e pode negar-se a participar desse processo. Entendemos e defendemos que esses são direitos de todos os possíveis colaboradores. Não negaremos, entretanto, que essa recusa deixa de alimentar a pluralidade de versões e atribuição de significados que desejávamos com o convite.

Essas foram algumas das inquietações que constituíram o nosso caminhar metodológico e que julgamos necessário compartilhar com nossos leitores e esse nosso modo de construir nossa metodologia nos auxiliou a pensar e estruturar as análises das narrativas que constituímos nas situações de entrevista. No primeiro texto nossas análises foram disparadas tanto por nossas cinco narrativas quanto por documentos oficiais, no qual problematizamos demandas para a criação e continuação dos cursos, negociações entre lideranças indígenas, SEE-SP e instituições formadoras, no nosso caso a USP e a Unesp e as ações provenientes dessas discussões e discutimos que a partir do momento que a proposta de educação escolar indígena do Estado de São Paulo a coloca como parte do sistema de educação do Estado, os mecanismos existentes no sistema passam a valer também para ela. No segundo texto analítico, elaborado a partir do nosso primeiro texto de análise, focamos nos pontos de tensionamento que nos sensibilizaram, destacando resistências, concepções e decorrências das ações que envolveram a criação dos cursos e a formação de professores nela proposta. Percebemos que na concepção da SEE-SP, quando os indígenas reivindicam escola em suas aldeias, a instituição entende que essa ação está diretamente relacionada à introdução dessa escola dentro de um sistema estadual de ensino, o que possivelmente não é o que os indígenas imaginavam inicialmente. (SILVA, 2019). Assim, nossas análises tanto apresentam um fluxo narrativo, relativo à nossa versão histórica sobre a criação dos primeiros cursos de formação indígena no estado de São Paulo quanto nossas sensibilizações teóricas, principalmente relacionados à História e à diferença, tensionamos alguns pontos que julgamos mais importantes.

\section{Considerações Finais}

Pode até ser que no início da elaboração de um projeto de pesquisa o referencial teórico-metodológico da História Oral seja percebido como uma motosserra ou uma faca. No entanto, nossa intenção foi problematizar, a partir da metáfora entre facas e motosserras, como uma metodologia de pesquisa foi construída durante o desenvolvimento de uma pesquisa de mestrado, sem a intenção de hierarquização das metodologias, sem ter que decidir entre uma ou outra e sem tomar a metodologia de pesquisa como dada a priori, pronta. No nosso modo de pensar a construção intencional da metodologia da pesquisa, em trajetória, facas, motosserras e tantas outras ferramentas são mobilizadas, sem hierarquias entre elas, e sim no sentido de que auxiliam o pesquisador na construção e desenvolvimento de sua pesquisa. Assim, a História Oral é aqui assumida como uma metodologia no sentido do como ela é praticada, em trajetória, em um contínuo movimento entre práticas anteriores. Nesse sentido, não se trata de estar entre facas e motosserras, entre História Oral ou tantas outras metodologias ou técnicas, mas de estarmos sensíveis e atentos às práticas de pesquisa para e no desenvolvimento da pesquisa. Desejamos que essas problematizações possam contribuir com a sempre saudável prática acadêmica de estudar e testar limites e potencialidades de referenciais metodológicos e a eles acrescentar algo, um estudo que exige atenção, respeito e sensibilidade. 


\section{Agradecimentos}

O presente trabalho foi realizado com apoio da Coordenação de Aperfeiçoamento de Pessoal de Nível Superior (Capes), com o Código de Financiamento 001.

\section{Referências}

ALBUQUERQUE JÚNIOR, D. M. História: a arte de inventar o passado. Bauru: Edusc, 2007.

ARANHA, C. S. G. Algumas parcerias na expressão criadora: obra de arte e história oral. Revista Pesquisa Qualitativa, Bauru, v. 2, n. 1, p. 49-54, 2006. Disponível em: https://editora.sepq.org.br/rpq/ article/view/15. Acesso em: 20 ago. 2020.

BARALDI, I. M. Retraços da educação matemática na região de Bauru (SP): uma história em construção. 2003. 288 f. Tese (Doutorado em Educação Matemática) - Instituto de Geociências e Ciências Exatas, Universidade Estadual Paulista, Rio Claro, 2003. Disponível em: https://repositorio. unesp.br/handle/11449/102158. Acesso em: 10 ago. 2020.

BLOCH, M. Apologia da história ou o ofício de historiador. Rio de Janeiro: Zahar, 2001.

CALVINO, I. As cidades invisíveis. São Paulo: Companhia das Letras, 1990.

DELGADO, L. A. N. História oral: memória, tempo e identidades. Belo Horizonte: Autêntica, 2006.

FERNANDES, D. N.; GARNICA, A. V. M. A Formação do professor de matemática no Maranhão: das cartas de uma cartografia possível. In: GARNICA, A. V. M. (org.). Cartografias contemporâneas: mapeando a formação de professores de matemática no Brasil. Curitiba: Appris, 2014. p. 153-178.

GARNICA, A. V. M. História oral como recurso para a pesquisa em educação matemática: um estudo de caso brasileiro. In: CONGRESSO IBEROAMERICANO DE EDUCAÇÃO MA̧TEMÁTICA, 5., 2005, Porto. Anais [...]. Porto: Associação de Professores de Matemática de Portugal, 2005. p. 1-12.

GARNICA, A. V. M. História oral e educação matemática. In: BORBA, M. C.; ARAÚJO, J. L. (org.). Pesquisa qualitativa em educação matemática. Belo Horizonte: Autêntica, 2004. p. 77-97.

GARNICA, A. V. M.; ROLKOUSKI, E. Breve mas verídica história de uma pesquisa sobre como o professor se torna o professor que é: (im)possibilidades e (in)conclusões. In: GARNICA, A. V, M. (org.). Cartografias contemporâneas: mapeando a formação de professores de matemática no Brasil. Curitiba: Appris, 2014. p. 87-128.

GARNICA, A. V. M.; MARTINS-SALANDIM, M. E. História oral e educação matemática: perspectiva e um projeto coletivo. In: RODEGHERO, C. S.; GRINBERG, L.; FROTSCHER, M. (org.). História oral e práticas educacionais. Porto Alegre: Editora da UFRGS, 2016. p. 181-194.

GONZALES, K. G. Formar professores que ensinam matemática: uma história do movimento das licenciaturas parceladas no Mato Grosso do Sul. 2017. Tese (Doutorado em Educação para a Ciência) - Faculdade de Ciências, Universidade Estadual Paulista, Bauru, 2017. Disponível em: https:// repositorio.unesp.br/handle/11449/151327. Acesso em: 10 ago. 2020.

HARTMANN, L. História, memória e performance em narrativas orais de crianças. In: RODEGHERO, C. S.; GRINBERG, L.; FROTSCHER, M. (org.). História oral e práticas educacionais. Porto Alegre: Editora da UFRGS, 2016. p. 107-124.

JENKINS, K. A história repensada. 4. ed. São Paulo: Contexto, 2017.

LE GOFF, J. História e memória. 6. ed. Lisboa: Edições 70, 2001. 
LLEWELLYN, K. R. De volta ao futuro: o poder político da história oral na educação. In: RODEGHERO, C. S.; GRINBERG, L.; FROTSCHER, M. (org.). História oral e práticas educacionais. Porto Alegre: Editora da UFRGS, 2016. p. 15-34.

MARTINS-SALANDIM, M. E. Grupo de pesquisa história oral e educação matemática: dos estudos sobre hermenêutica de profundidade. Histemat: revista de história da educação matemática, São Paulo, v. 4, n. 3. p. 133-149, 2018. Disponível em: http://histemat.com.br/index.php/HISTEMAT/ article/view/239. Acesso em: 10 ago. 2020.

MARTINS-SALANDIM, M. E. A interiorização dos cursos de matemática no estado de São Paulo: um exame da década de 1960. 2012. 374 f. Tese (Doutorado em Educação Matemática) - Instituto de Geociências e Ciências Exatas, Universidade Estadual Paulista, Rio Claro, 2012. Disponível em: https://repositorio.unesp.br/handle/11449/102107. Acesso em: 10 ago. 2020.

MAUAD, A. M. Memórias em movimento: a experiência com fontes orais e visuais do laboratório de história oral e imagem da UFF. In: RODEGHERO, C. S.; GRINBERG, L.; FROTSCHER, M. (org.). História oral e práticas educacionais. Porto Alegre: Editora da UFRGS, 2016. p. 205-220.

NEVES, L. A. Memória e hsitória: multiplicidade e singularidade na construção do documento oral. Cadernos CERU: série 2, São Paulo, v. 12, p. 23-30, 2001. Disponível em: http://www.revistas.usp.br/ ceru/article/view/75083. Acesso em: 10 ago. 2020.

NORA, P. Entre memória e história: a problematização dos lugares. Projeto História, São Paulo, v. 10, p. 7-28, dez. 1993. Disponível em: https://revistas.pucsp.br/revph/article/view/12101. Acesso em: 10 ago. 2020.

PATAI, D. História oral, feminismo e política. São Paulo: Letra e Voz, 2010.

PORTELLI, A. O que faz a história oral diferente. Projeto História, São Paulo, v. 14, p. 25-39, fev. 1997. Disponível em: https://revistas.pucsp.br/revph/article/view/11233/8240. Acesso em: 10 ago. 2020.

RICOEUR, P. A memória, a história, o esquecimento. Campinas: Editora da Unicamp, 2007.

SILVA, H.; SOUZA, L. A. A história oral na pesquisa em educação matemática. Bolema, Rio Claro, v. 20, n. 28, p. 139-162, 2007. Disponível em: https://www.redalyc.org/pdf/2912/291221871008.pdf. Acesso em: 10 ago. 2020.

SILVA, K. A. Primeiros cursos para formação de professores indígenas no estado de São Paulo: um estudo em história da educação matemática. 2019. Dissertação (Mestrado em Educação para a Ciência) - Faculdade de Ciências, Universidade Estadual, Bauru, 2019.

THOMPSON, P. A voz do passado: história oral. 3. ed. Rio de Janeiro: Paz e Terra, 2002.

THOMSON, A. Aos cinquenta anos: uma perspectiva internacional da história oral. In: FERREIRA, M. M.; FERNANDES, T. M.; ALBERTI, V. (org.). História oral: desafios do século XXI. Rio de Janeiro: Editora Fiocruz, 2000. p. 47-65.

VIANNA, C. R. Sem título. In: GARNICA, A. V, M. (org.). Cartografias contemporâneas: mapeando a formação de professores de matemática no Brasil. Curitiba: Appris, 2014. p. 67-86. 